\title{
III. Note on Variation in Leaves of Mulberry Trees.
}

A trextion bas frequently been drawn to the difference in type of leaves growing on different parts of trees, and under the heading of heterophylly it is a topic fomiliar to botanista. It is only recently, however, that it has become a subject for statistical investigation. We may refer, for example, to the researches of De Brugher on "light" and "shade" leares of the beech*, and to the measurements of A. Heyer on the needle of the pine embodied in Dr Ludwig's paper in the first number of Biometrikat. The present noto deals with a similar case; it is hoped that it may serve as a preliminary atudy for a moro extensive statistical investigation when further material is nert jear available. The importance of such investigations into a possible correlation between the cheracter and situation of like organs is manifest if leaves are to be used as "bomotypes" in the study of hornotyporit.

The leaves of the common Mulberry appear to vary greatly according to their position on the tree, if I may judge from five trees which I have examined, and three of which information has been sent me.

Fig. I shuws the usual, and greatly preponderating type of leaf, which on a large tree varies in size from about 3 to about 6 inches in length. In many there is a slight bulge or fulness at one place near the top, Fig. X, $A, B, C$ : so that the leaf could not be pressed without some overlapping. Fig. III shows the greatest variation from the usual type that I have found: and Fig. II an intermediate form.

So far as I have observed, the deeply incised leaves (Fig. III) are found (a) largely on amall twigs growing immediately from the main trunk and near its bottom, (b) occasionally on larger twigm or mall boughs growing among the luwer boughs: one has been found at the end of a low bough, but never high up on the tree.

The intermediate forms (Fig. II) are found (a) on small twigs along with No. III, (b) at the end of the lower boughs, and (c) apparontly occasionally, bat very rarely, at the end of higher boughs. The usual type is found in great preponderance over the whole tree: and the small twige generally show this type too, though it is possible to find twigs with more or less incised leaves only.

With the ausistance of Miss Eleanor Hobhouse the leaves of 8 mulberry trees of very different ages were exsmined. From these few troes it would appear that

(a) The age of the tree does not affect the matter: as the two youngest trees had very little variation, but the next in age had a verg great deal.

(b) Well-grown upright trees with no ground or trunk shuots seem to have but little variation.

(c) Where the greatest number of cut lesres appears, the most deeply-cut leares are also found.

(d) The lowest boughs and twigs have the greatest variation in reapect of inciaion.

(o) The types melt into one another, and it would I think be easy to make a complete scale between Fig. X with its three bulges, and Fig. III with its cmaciated form. In fact, the figures here given, if arranged according to the numbers in brackets, will form a very fairly continuous gradation from one extreme to the other; but I question whother any one of the trees examined would yield the complete scale.

AGNES FRY.

- Bot. Jaatboek Dodorieea te Gent, Vol. Ir. p. 116, 1899.

+ Biometrika, Vol. I. p. 20 et eeq. 

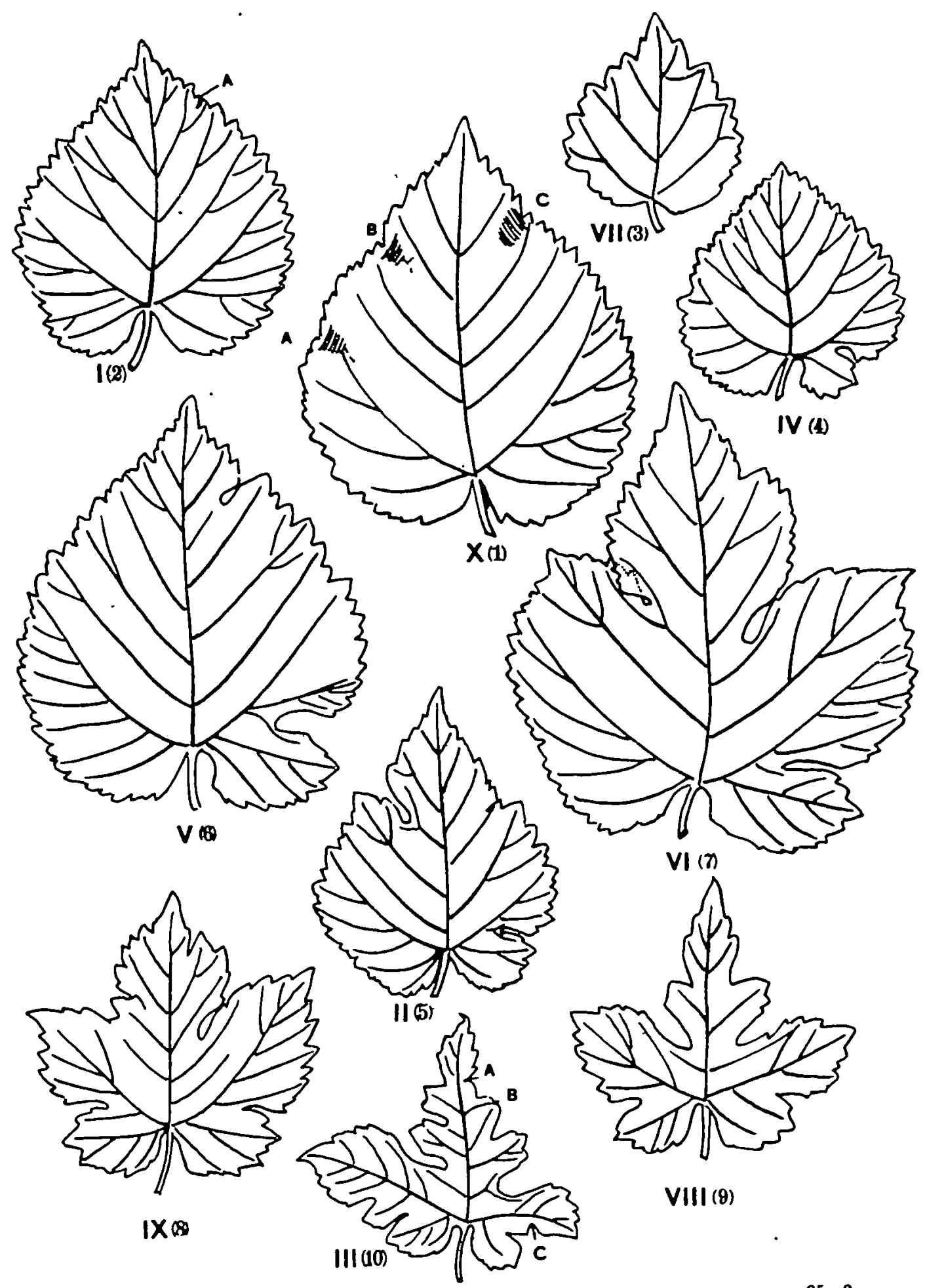

VIII (8) 